\title{
Whole blood aggregometry prior to Pipeline embolization device treatment of intracranial aneurysms: defining an optimal platelet inhibition cutoff value for clopidogrel
}

\author{
Paul M. Foreman, MD, ${ }^{1}$ Alejandro Enriquez-Marulanda, MD, ${ }^{2}$ James H. Mooney, MD, ${ }^{1}$ \\ Philip G. R. Schmalz, MD, ${ }^{1}$ Christoph J. Griessenauer, MD, ${ }^{3-5}$ John P. Deveikis, MD, ${ }^{2}$ and \\ Mark R. Harrigan, MD²
}

'Department of Neurosurgery, University of Alabama at Birmingham, Alabama; ${ }^{2}$ Beth Israel Deaconess Medical Center, Harvard Medical School, Boston, Massachusetts; ${ }^{3}$ Department of Neurosurgery, Geisinger, Danville, Pennsylvania; and ${ }^{4}$ Department of Neurosurgery and ${ }^{5}$ Research Institute of Neurointervention, Paracelsus Medical University, Salzburg, Austria

\begin{abstract}
OBJECTIVE Dual antiplatelet therapy is required for the treatment of intracranial aneurysms with the Pipeline embolization device (PED). Platelet function testing (PFT) is often used to assess the efficacy of the antiplatelet regimen prior to PED placement. The optimal impedance values for whole blood aggregometry in this setting have not been defined.

METHODS A retrospective review of a prospectively maintained database was performed for the years 2011-2015 to identify patients with intracranial aneurysms treated with the PED who underwent pretreatment PFT using whole blood aggregometry. Antiplatelet therapy was not altered based on PFT results; all patients remained on standard doses of aspirin and clopidogrel. Clinical, radiographic, and laboratory data were analyzed to identify the optimal cutoff impedance value for clopidogrel responsiveness using the receiver operating characteristic curve and Youden's index.

RESULTS Forty-nine patients underwent 53 endovascular procedures for the treatment of 76 aneurysms using the PED. The majority of these aneurysms were located in the anterior circulation (90.8\%) and affected the internal carotid artery $(89.5 \%)$. Patients in 30 procedures $(56.6 \%)$ were identified as clopidogrel responders based on the manufacturer cutoff value $(<6 \Omega)$. Thromboembolic complications occurred in $13(24.5 \%)$ procedures; patients in $6(11.3 \%)$ cases were symptomatic and those in $3(5.7 \%)$ cases had ischemic strokes. Eleven of the $13(84.6 \%)$ thromboembolic complications occurred in clopidogrel nonresponders. An impedance value of $\geq 6 \Omega$ was independently associated with thromboembolic complications. The optimal electrical impedance value was identified as $\geq 6 \Omega$ (sensitivity $84.6 \%$, specificity $70.0 \%$, area under the curve 0.77 ) for identifying clopidogrel nonresponders.
\end{abstract}

CONCLUSIONS Thromboembolic complications are more common following PED placement in patients who do not respond adequately to clopidogrel. Clopidogrel nonresponders can be identified using pretreatment whole blood aggregometry. The optimal cutoff value to categorize a patient as a clopidogrel nonresponder when using whole blood aggregometry is $\geq 6 \Omega$.

https://thejns.org/doi/abs/10.3171/2018.6.JNS181044

KEYWORDS aneurysm; Pipeline; clopidogrel; platelet function test; whole blood aggregometry; thromboembolism; complication; vascular disorders

$\mathrm{T}$ HE Pipeline embolization device (PED) is a flow-diverting stent that was approved by the FDA in 2011 for the treatment of large aneurysms of the intracranial internal carotid artery (ICA). The stent is a bimetallic self-expanding braid that provides 30\%-35\% surface coverage. The stent diverts blood flow away from the aneurysm and allows for endothelialization across the neck of the aneurysm, effectively reconstructing the parent artery. The relatively high metallic surface area of the stent (3-5 times that of a traditional intracranial stent) neces-

ABBREVIATIONS DAPT = dual antiplatelet therapy; DSA = digital subtraction angiography; ICA = internal carotid artery; LTA = light transmission aggregometry; $m$ RS = modified Rankin Scale; PED = Pipeline embolization device; $\mathrm{PFT}=$ platelet function testing; $\mathrm{PRU}=\mathrm{P} 2 \mathrm{Y} 12$ reaction unit; $\mathrm{ROC}=$ receiver operating characteristic; $\mathrm{SAH}=$ subarachnoid hemorrhage; WBA = whole blood aggregometry.

SUBMITTED April 17, 2018. ACCEPTED June 11, 2018.

INCLUDE WHEN CITING Published online November 16, 2018; DOI: 10.3171/2018.6.JNS181044. 
sitates dual antiplatelet therapy (DAPT) to reduce the risk of thromboembolic complications. The most commonly employed DAPT regimen consists of aspirin and clopidogrel. ${ }^{8}$ However, growing concern for clopidogrel resistance or hyporesponsiveness has led many clinicians to use pretreatment platelet function testing (PFT) to guide antiplatelet therapy. ${ }^{1,3,5,8}$

The primary role of PFT prior to neuroendovascular procedures is to evaluate the inhibition of platelets as a result of antiplatelet therapy. Commonly used platelet function tests include light transmission aggregometry (LTA), whole blood aggregometry (WBA), and point-ofcare testing, such as the VerifyNow assay (Accriva Diagnostics). ${ }^{8}$ The nonstandardized use of PFT and absence of formal definitions has led to inconsistency in the literature regarding the prevalence of antiplatelet resistance..$^{13} \mathrm{~A}$ recent literature review comparing platelet function tests for the assessment of aspirin and clopidogrel response concluded that comparing assay results to the gold standard, LTA, was irrelevant and that assays should be tested to determine cutoff values that predict clinical outcomes. ${ }^{13}$ The current study seeks to define the optimal clopidogrel response cutoff value as identified using WBA in patients undergoing PED placement for the treatment of intracranial aneurysms. The study is uniquely suited to evaluate this relationship because antiplatelet therapy was not altered following PFT; all patients remained on standard dosing of aspirin (325 mg daily) and clopidogrel (75 mg daily).

\section{Methods}

A retrospective review of a prospectively maintained neuroendovascular database was performed at a single academic institution in the United States from 2011 to 2015 to identify patients with at least 1 intracranial aneurysm treated with the PED. Inclusion criteria: adult patients $(\geq$ 18 years) with an intracranial aneurysm who underwent pretreatment WBA PFT prior to treatment with the PED. Ruptured and unruptured aneurysms were included. All aneurysm morphologies and intracranial locations were included. The following data were collected: patient demographics, aneurysm characteristics, PFT results, antiplatelet regimen, procedural details, complications, angiographic outcome, and functional outcome. Institutional review board approval was obtained. The preprocedural anticoagulation regimen, intraprocedural treatment of thromboembolism, and outcome assessment were done according to protocol. ${ }^{7}$

\section{Procedure Details}

Patients with unruptured intracranial aneurysms received aspirin $325 \mathrm{mg}$ daily and clopidogrel $75 \mathrm{mg}$ daily for a minimum of 3 days before the intervention. Those with ruptured aneurysms were treated within 24-48 hours of presentation and received a loading dose of aspirin 650 $\mathrm{mg}$ and clopidogrel $600 \mathrm{mg}$ before the intervention. The last dose of clopidogrel was given the morning of PFT. PFT was performed using WBA (model 700, CHRONOLOG) prior to treatment. Clopidogrel nonresponders were identified based on established cutoff values guided by manufacturer recommendations. WBA monitors the proportional increase in impedance between 2 electrodes immersed in whole blood due to aggregation of stimulated platelets. The change in resistance after agonist administration is quantified in ohms $(\Omega)$; an increase in impedance is directly proportional to the mass of the platelet aggregate. The response pattern is compared with established norms provided by the manufacturer; a patient with WBA impedance $<6 \Omega$ after administration of ADP (adenosine diphosphate) is regarded as a clopidogrel responder. Activated clotting time was used to guide heparin administration during the procedure, with a target of 250-300 seconds; typical dosing consisted of a 3000- to 5000-U bolus at the beginning of the procedure, with hourly dosing of $1000 \mathrm{U}$.

No changes were made to the antiplatelet regimen based on the results of the PFT. Patients remained on aspirin $325 \mathrm{mg}$ daily and clopidogrel $75 \mathrm{mg}$ daily regardless of the PFT result. Dual antiplatelet therapy was continued for at least 6 months after the procedure and aspirin indefinitely thereafter.

\section{Complications}

Thromboembolic complications included both intraprocedural and postprocedural complications up to the last follow-up. A thromboembolic complication was considered symptomatic if transient or permanent signs and symptoms were attributable to the event. Intraprocedural thromboembolic complications were identified on digital subtraction angiography (DSA) as thrombus formation (i.e., intraarterial filling defects), delayed filling of a vessel, or vessel dropout. Intraprocedural thromboembolism was treated at the discretion of the interventionalist and could include additional antiplatelet medication (i.e., abciximab), anticoagulation, thrombolytics, mechanical thrombectomy, or observation. Postprocedural thromboembolic complications were identified using a combination of clinical and radiographic data. Postprocedural imaging was performed at the discretion of the treating physician and was only obtained due to clinical concern; radiographic screening of asymptomatic patients was not performed.

Hemorrhagic complications occurring until last followup were included. Hemorrhagic complications were identified intraoperatively as contrast extravasation on DSA or on postprocedure imaging. Hemorrhages were counted as symptomatic if the patient reported symptoms or demonstrated signs attributable to a hemorrhage.

\section{Outcomes}

Angiographic outcome was assessed using DSA, MRA, or CTA. Aneurysm occlusion after PED treatment was categorized as complete $(100 \%)$, near-complete $(90 \%-$ $99 \%)$, or partial $(<90 \%)$ occlusion. Functional outcome was assessed using the modified Rankin Scale (mRS) at last follow-up.

\section{Statistical Analysis}

Results of categorical variables are reported as proportions. Continuous variables are reported as the mean \pm 
standard deviation or median (IQR) based on the distribution of the data assessed by the Shapiro-Wilk test. A receiver operating characteristic (ROC) curve analysis was performed to assess the diagnostic accuracy of the WBA impedance $(\Omega)$ measurements for thromboembolic complications. To identify the optimal impedance cutoff values, we used Youden's index. A univariate comparison of baseline patient and aneurysm characteristics was performed between the patients who experienced thromboembolic complications and those who did not to identify potential factors associated with higher risk of this event. The chi-square test was used for the analysis of categorical variables. The 2-sample t-test or the Mann-Whitney test was used for comparing continuous variables according to the normality distribution. Those parameters that had a significance level $<0.1$ on univariate analysis were then used in a multivariate Firth logistic regression to control the effect of an impedance measurement $\geq 6 \Omega$ effect on the risk of thromboembolic complications. Due to the limited number of outcome events $(n=13)$, the logistic regression models were limited to the impedance value and one additional factor. All statistical analyses were performed using Stata software (StataCorp); $p<0.05$ was considered statistically significant.

\section{Results}

Forty-nine patients underwent 53 PED procedures for the treatment of 76 intracranial aneurysms. The mean age was $56.7 \pm 10.9$ years. The majority of these aneurysms were located in the anterior circulation (90.8\%), affected the ICA $(89.5 \%)$, and were not associated with subarachnoid hemorrhage (SAH; 79.6\%). Most aneurysms were saccular $(75.0 \%)$ in morphology. Patients in $51(96.2 \%)$ of the procedures were identified as aspirin responders and those in $30(56.6 \%)$ procedures were identified as clopidogrel responders (WBA impedance $<6 \Omega$ ). The median clopidogrel impedance value was $4 \Omega$ (IQR 4-9 $\Omega$; Table 1).

\section{Complications}

Fifteen $(28.3 \%)$ procedures were complicated by thromboembolic or hemorrhagic complications. Thirteen (24.5\%) thromboembolic complications occurred overall, produced signs or symptoms in $6(11.3 \%)$ procedures, and resulted in an ischemic stroke in $3(5.7 \%)$ procedures. Eleven of the $13(84.6 \%)$ thromboembolic complications occurred in patients identified as clopidogrel nonresponders. In univariate analysis, an impedance value of $\geq 6 \Omega$ was significantly associated with thromboembolic complications $(\mathrm{p}=0.001)$, and previous treatment was significantly associated with the absence of thromboembolic complications $(p=0.02)$. In multivariate logistic regression analysis, an impedance value of $\geq 6 \Omega$ remained significantly associated with thromboembolic complications (Tables 2 and 3).

Hemorrhagic complications occurred in 5 (9.4\%) procedures and produced signs or symptoms in $4(7.5 \%)$. Four $(80.0 \%)$ of 5 hemorrhagic complications occurred in clopidogrel nonresponders.

Of the 10 patients with a history of SAH, 1 experienced a procedural complication. The posttreatment compli-
TABLE 1. Clinical and radiographic data

\begin{tabular}{|c|c|}
\hline & Value \\
\hline No. of patients & 49 \\
\hline Mean age, yrs & $56.7 \pm 10.9$ \\
\hline Smoking history & $23(46.9)$ \\
\hline HTN & $31(63.3)$ \\
\hline Diabetes mellitus & $7(14.3)$ \\
\hline Renal failure & $1(2.0)$ \\
\hline Family history of aneurysm & $10(20.4)$ \\
\hline Multiple intracranial aneurysms & $22(44.9)$ \\
\hline \multicolumn{2}{|l|}{ Previous SAH } \\
\hline No & $39(79.6)$ \\
\hline$\leq 2$ wks & $1(2.0)$ \\
\hline$>2$ wks & $9(18.4)$ \\
\hline \multicolumn{2}{|l|}{ Previous treatment } \\
\hline Coil embolization & $10(20.4)$ \\
\hline Microsurgical clipping & $2(4.1)$ \\
\hline Coiling \& clipping & $1(2.0)$ \\
\hline \multicolumn{2}{|l|}{ Pretreatment mRS score } \\
\hline 0 & $25(51.0)$ \\
\hline 1 & $14(28.6)$ \\
\hline 2 & $8(16.3)$ \\
\hline 3 & $2(4.1)$ \\
\hline No. of treated aneurysms & 76 \\
\hline \multicolumn{2}{|l|}{ Side } \\
\hline $\mathrm{Lt}$ & $44(57.9)$ \\
\hline Rt & $29(38.2)$ \\
\hline NA & $3(3.9)$ \\
\hline \multicolumn{2}{|l|}{ Circulation } \\
\hline Anterior & $69(90.8)$ \\
\hline Posterior & 7 (9.2) \\
\hline \multicolumn{2}{|l|}{ Aneurysm location } \\
\hline ICA & $68(89.5)$ \\
\hline Petrous & $1(1.5)$ \\
\hline Cavernous & $18(26.5)$ \\
\hline Ophthalmic & $33(48.5)$ \\
\hline Communicating & $16(23.5)$ \\
\hline $\mathrm{BA}$ & $3(3.9)$ \\
\hline VA & $2(2.6)$ \\
\hline PCA & $2(2.6)$ \\
\hline ACA & $1(1.3)$ \\
\hline \multicolumn{2}{|l|}{ Aneurysm morphology } \\
\hline Saccular & $57(75.0)$ \\
\hline Fusiform/dissecting/blister & $19(25.0)$ \\
\hline Median max diameter, mm & $8($ IQR 4-13) \\
\hline Intraaneurysmal thrombus & $7(9.2)$ \\
\hline No. of procedures & 53 \\
\hline \multicolumn{2}{|l|}{ No. of PEDs placed } \\
\hline 1 & $40(75.5)$ \\
\hline 2 & $7(13.2)$ \\
\hline 3 & $6(11.3)$ \\
\hline
\end{tabular}

CONTINUED ON PAGE 1440 » 
» CONTINUED FROM PAGE 1439

TABLE 1. Clinical and radiographic data

\begin{tabular}{|c|c|}
\hline & Value \\
\hline No. of procedures (continued) & 53 \\
\hline Adjunctive coil during PED embolization & $10(18.9)$ \\
\hline Aspirin responder & $51(96.2)$ \\
\hline Clopidogrel responder & $30(56.6)$ \\
\hline Median clopidogrel impedance value $(\Omega)$ & 4 (IQR 4-9) \\
\hline $\begin{array}{l}\text { Procedures complicated by thromboembo- } \\
\text { lism \&/or hemorrhage }\end{array}$ & $15(28.3)$ \\
\hline Thromboembolic complications & $13(24.5)$ \\
\hline $\begin{array}{l}\text { Symptomatic thromboembolic complica- } \\
\text { tions }\end{array}$ & $6(11.3)$ \\
\hline Ischemic stroke & $3(5.7)$ \\
\hline \multicolumn{2}{|l|}{ Timing of complication } \\
\hline Intraprocedural & $5(9.4)$ \\
\hline Intra- \& postprocedural & $3(5.7)$ \\
\hline Postprocedural & $5(9.4)$ \\
\hline Hemorrhagic complications & $5(9.4)$ \\
\hline Symptomatic hemorrhagic complications & $4(7.5)$ \\
\hline \multicolumn{2}{|l|}{ Type of hemorrhage } \\
\hline Intracerebral hematoma w/ IVH & $1(1.9)$ \\
\hline Intracerebral hematoma \& SDH & $1(1.9)$ \\
\hline $\mathrm{SAH}$ & $2(3.8)$ \\
\hline SAH w/ IVH & $1(1.9)$ \\
\hline Aneurysm imaging follow-up & 76 \\
\hline \multicolumn{2}{|l|}{ 6-mo imaging follow-up* } \\
\hline $\begin{array}{l}\text { Median elapsed time to 6-mo imaging } \\
\text { follow-up (days) }\end{array}$ & 181 (IQR 161-199) \\
\hline \multicolumn{2}{|l|}{ Occlusion status } \\
\hline Occluded (100\%) & $51(76.1)$ \\
\hline Near-completely occluded (90-100\%) & $8(11.9)$ \\
\hline Incompletely occluded (<90\%) & $8(11.9)$ \\
\hline \multicolumn{2}{|l|}{ Last imaging follow-up $\dagger$} \\
\hline $\begin{array}{l}\text { Median elapsed time to last imaging } \\
\text { follow-up (days) }\end{array}$ & 666 (IQR 261.5-986) \\
\hline \multicolumn{2}{|l|}{ Occlusion status } \\
\hline Occluded (100\%) & $55(80.9)$ \\
\hline Near completely occluded (90-100\%) & $6(8.8)$ \\
\hline Incompletely occluded (<90\%) & $7(10.3)$ \\
\hline Re-treatment & $3(3.9)$ \\
\hline In-PED stenosis on follow-up $\ddagger$ & 53 \\
\hline Yes & $4(8.7)$ \\
\hline Clinical follow-up & 53 \\
\hline $\begin{array}{l}\text { Median elapsed time to last imaging follow- } \\
\text { up (days) }\end{array}$ & 648 (IQR 183-958) \\
\hline \multicolumn{2}{|l|}{ mRS score at last follow-up } \\
\hline 0 & $31(58.5)$ \\
\hline $1-2$ & $16(30.2)$ \\
\hline $3-5$ & $5(9.4)$ \\
\hline 6 & $1(1.9)$ \\
\hline
\end{tabular}

CONTINUED IN NEXT COLUMN »

\section{» CONTINUED FROM PREVIOUS COLUMN}

\section{TABLE 1. Clinical and radiographic data}

$\mathrm{ACA}=$ anterior cerebral artery; $\mathrm{BA}=$ basilar artery; $\mathrm{HTN}=$ hypertension; IVH $=$ intraventricular hemorrhage; $\mathrm{NA}=$ not available; $\mathrm{PCA}=$ posterior cerebral artery; $\mathrm{SDH}=$ subdural hematoma; $\mathrm{VA}=$ vertebral artery.

Values are presented as number (\%) unless stated otherwise. Mean values are reported as the mean \pm SD.

${ }^{*}$ Missing follow-up imaging data on 9 aneurysms. † Missing follow-up imaging data on 8 aneurysms. $\ddagger$ Missing follow-up imaging data on 7 procedures.

cation was thromboembolic in nature and resulted in a middle cerebral artery ischemic stroke; this patient was a clopidogrel nonresponder.

\section{Outcomes}

At last imaging follow-up (median 666 days, IQR 261.5-986 days), 55 (80.9\%) aneurysms were completely occluded and $6(8.8 \%)$ were near-completely occluded. Instent stenosis was present in $4(8.7 \%)$ cases; patients in 2 of the 4 cases were clopidogrel nonresponders.

At last clinical follow-up (median 648 days, IQR 183958 days), patients in 31 (58.5\%), $16(30.2 \%)$, and $5(9.4 \%)$ procedures had mRS scores of 0,1 or 2 , and 3-5, respectively; the patient in 1 procedure $(1.9 \%)$ had died.

\section{Impedance Cutoff Value}

The ROC curve and the Youden's index identified $\geq$ $6 \Omega$ as the optimal cutoff value for detecting clopidogrel nonresponders using thromboembolic complications as the outcome of interest (area under the curve 0.77). This resulted in a sensitivity of $84.6 \%$, specificity of $70.0 \%$, likelihood ratio positive 2.8 , and likelihood ratio negative 0.2 (Figs. 1 and 2).

\section{Discussion}

Dual antiplatelet therapy is standard of care for the prevention of thromboembolic complications associated with PED treatment of intracranial aneurysms. The most commonly used regimen consists of aspirin and clopidogrel. While aspirin remains the unwavering component of DAPT with nearly all studies investigating antiplatelet medication in neuroendovascular procedures including aspirin, clopidogrel is limited by incomplete activation, leading to ineffective platelet inhibition in some patients. ${ }^{12}$ This limitation is related to genetic polymorphisms within the CYP2C19 isoenzyme, drug-drug interactions, and clinical factors that increase platelet reactivity. ${ }^{12}$ In 2010 , the FDA released a boxed warning notifying clinicians of the diminished antiplatelet effects in poor metabolizers of clopidogrel. ${ }^{10}$ Concern for incomplete platelet inhibition has generated interest in pretreatment PFT to assess the efficacy of antiplatelet regimens. For the years included in the study (2011-2015), tailoring of antiplatelet therapy based on the results of a PFT was not performed. Despite some clinicians adopting the practice from the cardiology literature, ${ }^{16,17}$ convincing evidence was not available for the PED. After an internal review and participation in a multicenter study that demonstrated a significantly 
increased risk of thromboembolism in clopidogrel nonresponders who remain on standard clopidogrel dosing, ${ }_{1}$ this practice has been revised at our institution. Currently, at our institution, all patients treated with the PED undergo pretreatment WBA, and clopidogrel nonresponders are transitioned to ticagrelor or prasugrel. Some experienced centers continue to place PEDs for the treatment of aneurysms without pretreatment PFT, and it is debated if pretreatment PFT represents standard of care in this setting. This debate lies outside the scope of this article but considering the available data in support of PFT, ${ }^{1,3}$ we regard pretreatment PFT prior to PED placement as mandatory with few exceptions. Other centers have adopted alternative ADP antagonists (i.e., ticagrelor) as a first-line component of DAPT (with aspirin) given its more consistent platelet inhibition. We feel that this approach is valid, but we continue to use clopidogrel as a first-line treatment given its affordability and the field's familiarity with the medication.

Platelet reactivity during antiplatelet therapy may be quantified using a PFT, and a majority of neuroendovascular specialists utilize pretreatment PFT to guide antiplatelet therapy prior to PED treatment of intracranial aneurysms. ${ }^{8,12}$ The most common methods include the pointof-care test VerifyNow, LTA, and the focus of the current investigation, WBA. A 2015 randomized controlled trial of patients treated with stent-assisted coil embolization of intracranial aneurysms found that modifying patients' antiplatelet therapy based on pretreatment VerifyNow results reduced the rate of thromboembolic events without an increase in bleeding. ${ }^{11}$ The use of PFTs in the setting of PED treatment of aneurysms is further supported by retrospective studies. ${ }^{1,3,6,15}$ Daou et al. evaluated the use of VerifyNow testing prior to placement of the PED and found significantly increased thromboembolic and hemorrhagic complication rates when the $\mathrm{P} 2 \mathrm{Y} 12$ reaction unit (PRU) was $>240$ or $<60$, respectively. However, this study was limited by a lack of a control group. ${ }^{3}$ A 2017 study by Adeeb et al. found that the highest rate of thromboembolic complications occurred in patients identified as clopidogrel nonresponders who remained on clopidogrel without dosage adjustments. ${ }^{1}$ This thromboembolic risk was significantly less in clopidogrel responders and clopidogrel nonresponders who were given a clopidogrel boost dose or switched to ticagrelor. The authors concluded that identifying clopidogrel nonresponders and initiating an alternative antiplatelet strategy may mitigate thromboembolic risk. This was a multicenter study and thus utilized various types of platelet function tests; however, no significant differences were identified between different platelet function tests.

Whole blood aggregometry has been shown to be more sensitive to the effect of antiplatelet therapy than LTA. ${ }^{13,14}$ It has also been reported that WBA is superior to LTA to assess clopidogrel response. ${ }^{4,13}$ Whole blood aggregometry measures electrical impedance between 2 electrodes submerged in whole blood. Following the administration of a platelet agonist (i.e., ADP), platelets aggregate on the electrodes and increase electrical impedance $(\Omega)$. The greater the platelet aggregation, the greater the impedance value. These values are then compared to standardized values
TABLE 2. Univariate analysis of factors associated with thromboembolic complications by procedure $(n=53)$

\begin{tabular}{|c|c|c|c|}
\hline & \multicolumn{2}{|c|}{ Thromboembolic Complications } & \multirow{2}{*}{$\begin{array}{c}\mathrm{p} \\
\text { Value }\end{array}$} \\
\hline & No & Yes & \\
\hline No. of procedures & $40(75.5)$ & $13(24.5)$ & \\
\hline Age, yrs & $56.2 \pm 11.6$ & $53.7 \pm 11.7$ & 0.49 \\
\hline Smoking history & $17(42.5)$ & $9(69.2)$ & 0.09 \\
\hline HTN & $25(62.5)$ & $7(53.8)$ & 0.58 \\
\hline Diabetes mellitus & $6(15.0)$ & $2(15.4)$ & 0.97 \\
\hline Renal failure & $0(0.0)$ & $1(7.7)$ & 0.08 \\
\hline Family history & $10(25.0)$ & $1(7.7)$ & 0.18 \\
\hline $\begin{array}{l}\text { Multiple intracranial aneu- } \\
\text { rysms }\end{array}$ & $20(50.0)$ & $6(46.1)$ & 0.81 \\
\hline Previous SAH & & & 0.48 \\
\hline No & $31(77.5)$ & $12(92.3)$ & \\
\hline$\leq 2 \mathrm{wks}$ & $1(2.5)$ & $0(0.0)$ & \\
\hline$>2$ wks & $8(20.0)$ & $1(7.7)$ & \\
\hline Previous treatment & $12(30.0)$ & $0(0.0)$ & 0.02 \\
\hline Pretreatment mRS score & & & 0.16 \\
\hline 0 & $23(57.5)$ & $4(30.8)$ & \\
\hline 1 & $11(27.5)$ & $5(38.4)$ & \\
\hline 2 & $4(10.0)$ & $4(30.8)$ & \\
\hline 3 & $2(5.0)$ & $1(4.3)$ & \\
\hline Aneurysm side location & & & 0.23 \\
\hline Lt & $24(60.0)$ & $6(46.1)$ & \\
\hline $\mathrm{Rt}$ & $13(32.5)$ & $7(53.9)$ & \\
\hline NA & $3(7.5)$ & $0(0.0)$ & \\
\hline $\begin{array}{l}\text { Aneurysm circulation loca- } \\
\text { tion }\end{array}$ & & & 0.1 \\
\hline Anterior & $33(82.5)$ & $13(100.0)$ & \\
\hline Posterior & $7(17.5)$ & $0(0.0)$ & \\
\hline Aneurysm morphology & & & 0.66 \\
\hline Saccular & $25(62.5)$ & $9(69.2)$ & \\
\hline Fusiform/dissecting/blister & $15(37.5)$ & $4(30.8)$ & \\
\hline Median max diameter, mm & 8 (IQR 6-18) & 11 (IQR 7-16) & 0.58 \\
\hline Median neck size, $\mathrm{mm}^{*}$ & 4 (IQR 3-5) & 5 (IQR 2.8-5.4) & 0.71 \\
\hline Daughter sac & $7(17.5)$ & $1(7.7)$ & 0.39 \\
\hline Intra-aneurysmal thrombus & $4(10.0)$ & $2(15.4)$ & 0.6 \\
\hline $\begin{array}{l}\text { Adjunctive coil during PED } \\
\text { embolization }\end{array}$ & $9(22.5)$ & $1(7.7)$ & 0.24 \\
\hline No. of PEDs placed & & & 0.87 \\
\hline 1 & $30(75.0)$ & $10(76.9)$ & \\
\hline 2 & $5(12.5)$ & $2(15.4)$ & \\
\hline 3 & $5(12.5)$ & $1(7.7)$ & \\
\hline $\begin{array}{l}\text { Balloon angioplasty to open } \\
\text { device }\end{array}$ & $4(10.0)$ & $4(30.8)$ & 0.07 \\
\hline Impedance $\geq 6 \Omega$ & $12(30.0)$ & $11(84.6)$ & 0.001 \\
\hline
\end{tabular}

Values are presented as the number of procedures (\%) unless stated otherwise. Categorical values were compared using the chi-square test. Median values were compared using the 2 -sample t-test. Median values. Median values were compared using the Mann-Whitney. Boldface type indicates statistical significance.

* Data were missing for 17 procedures. 
TABLE 3. Multivariate logistic regression of factors associated with thromboembolic complications

\begin{tabular}{lcc}
\hline \multicolumn{1}{c}{ Parameter } & OR $(95 \% \mathrm{Cl})$ & $\mathrm{p} \mathrm{Value}$ \\
\hline Model 1 & & \\
\hline Impedance $\geq 6 \Omega$ & $19.6(3.74-102.33)$ & $<0.001$ \\
\hline Previous treatment & $0.03(0.001-0.65)$ & 0.025 \\
\hline Model 2 & & \\
\hline Impedance $\geq 6 \Omega$ & $10.8(2.27-51.44)$ & 0.003 \\
\hline Smoking history & $3.20(0.75-13.6)$ & 0.11 \\
\hline Model 3 & & \\
\hline Impedance $\geq 6 \Omega$ & $9.58(2.07-44.3)$ & 0.004 \\
\hline Renal failure & $3.57(0.13-97.2)$ & 0.45 \\
\hline Model 4 & \\
\hline Impedance $\geq 6 \Omega$ & $9.28(2.04-42.2)$ & 0.004 \\
\hline Balloon angioplasty to open device & $3.04(0.55-16.6)$ & 0.2 \\
\hline
\end{tabular}

(<6 $\Omega$ for clopidogrel responders) from the manufacturer to categorize patients as responders or nonresponders. In the present study, we performed WBA in patients undergoing PED placement but did not adjust antiplatelet therapy based on the WBA results. This allowed a unique look at the thromboembolic risk associated with a particular impedance value. The data were analyzed using a ROC curve and Youden's index and identified $\geq 6 \Omega$ as the optimal cutoff value to categorize a patient as a clopidogrel nonresponder with regard to thromboembolic risk; it is noteworthy that this is identical to the manufacturer's suggested cutoff value. Platelet function testing using WBA allows the clinician to evaluate the efficacy of antiplatelet thera- py and tailor it to a desired effect, highlighting the role of individualized medicine in the treatment of cerebral aneurysms.

Interestingly, hemorrhagic complications were more common in clopidogrel nonresponders (4/5), and 3 of the 4 nonresponders with hemorrhagic complications also experienced a thromboembolic complication. It is conceivable that this paradox is explained by a thromboembolic complication starting a cascade of events that includes ischemic brain and additional antithrombotic therapy (i.e., abciximab) that then predisposes the patient to a hemorrhagic complication. However, small numbers preclude definitive statements. A somewhat similar study evaluating light transmission aggregometry prior to PED placement reported a hemorrhagic complication rate of $7 \%(1 / 15)$ among nonresponders as compared with $5 \%$ (4/80) in responders; this difference was not significant. ${ }^{2}$ However, this contrasts with the findings of Daou et al. who reported that a PRU $<60$ was a significant predictor of hemorrhagic complications.

\section{Limitations}

The most significant limitations of the present study are the retrospective design and relatively small number of patients. Retrospective studies are limited by incomplete data, recall bias, and unidentified confounders, while small patient numbers limit the power of the study. Dual antiplatelet therapy for a minimum of 3 days could lead to an overestimation of clopidogrel nonresponders as duration of clopidogrel therapy is known to impact clopidogrel responsiveness, with longer duration associated with increased responsiveness. ${ }^{9}$ Some authors have recommended at least 5 days of DAPT prior to intervention when the

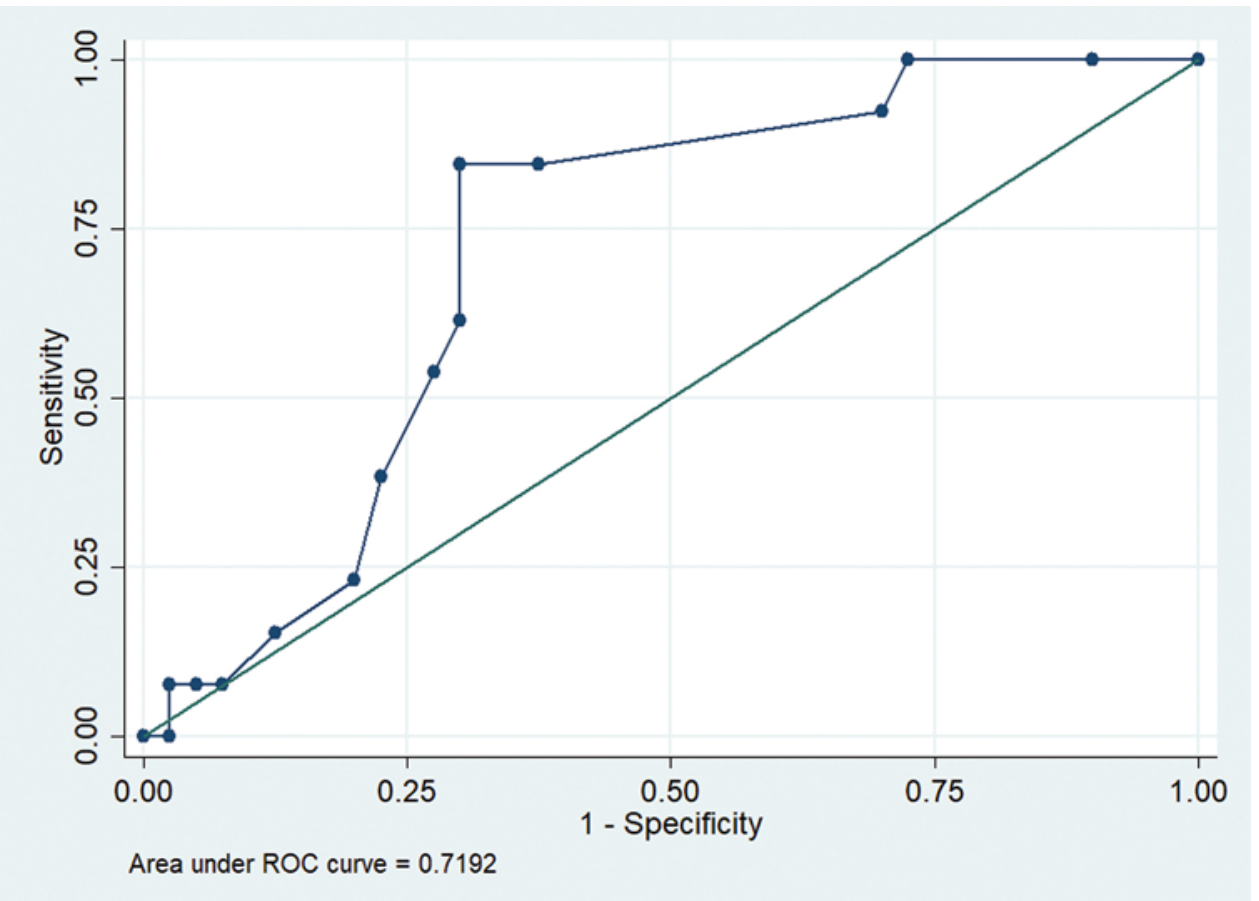

FIG. 1. ROC curve with impedance values plotted as a continuous variable. Figure is available in color online only. 


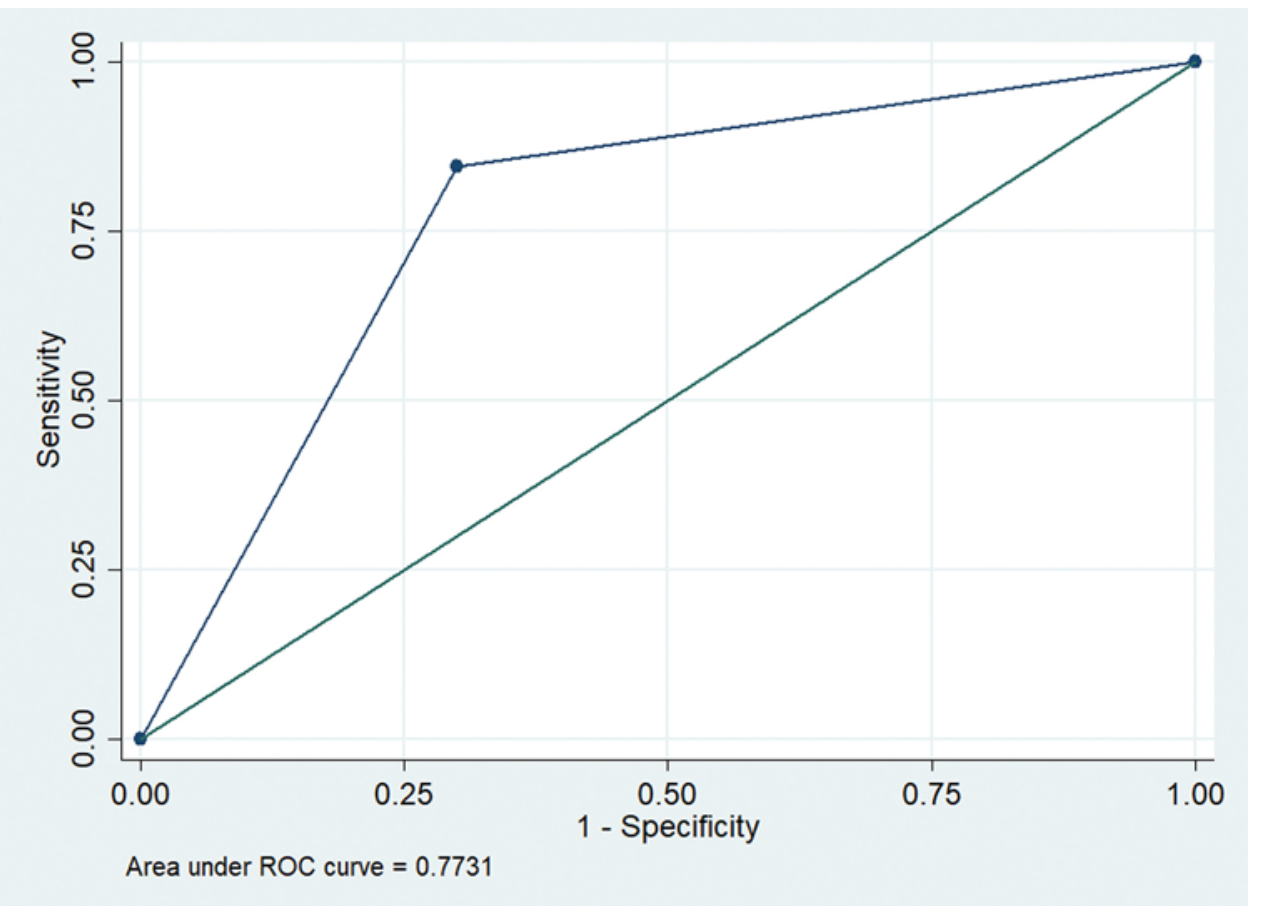

FIG. 2. ROC curve with $6 \Omega$, as determined by Youden's index, selected as the cutoff value to categorize impedance as a binary variable resulting in an area under the curve of 0.77 . Figure is available in color online only.

clinical situation allows. ${ }^{12}$ During the included years of the study (2011-2015), a single patient was treated with Pipeline Flex. It is possible that use of the older-generation device contributed to the procedural complication rate reported herein, and caution should be used when generalizing the results to new-generation devices. A lack of radiographic screening for thromboembolic and hemorrhagic complications could miss clinically silent events. The generalizability of the results is also limited given that the study was performed at a single institution.

\section{Conclusions}

Thromboembolic complications are more common following PED placement for the treatment of intracranial aneurysms in patients who do not respond adequately to clopidogrel. Clopidogrel nonresponders can be identified using pretreatment WBA. The optimal cutoff value to categorize a patient as a clopidogrel nonresponder when using WBA is $\geq 6 \Omega$.

\section{References}

1. Adeeb N, Griessenauer CJ, Foreman PM, Moore JM, Shallwani $\mathrm{H}$, Motiei-Langroudi R, et al: Use of platelet function testing before Pipeline embolization device placement: a multicenter cohort study. Stroke 48:1322-1330, 2017

2. Adeeb N, Gupta R, Schneider AM, Leadon M, Enriquez A, Griessenauer CJ, et al: Defining a clopidogrel response cut-off value using light transmission aggregometry before Pipeline embolization of unruptured intracranial aneurysms. World Neurosurg 113:e146-e152, 2018

3. Daou B, Starke RM, Chalouhi N, Barros G, Tjoumakaris S, Rosenwasser RH, et al: P2Y12 reaction units: effect on hem- orrhagic and thromboembolic complications in patients with cerebral aneurysms treated with the Pipeline embolization device. Neurosurgery 78:27-33, 2016

4. Dyszkiewicz-Korpanty A, Olteanu H, Frenkel EP, Sarode R: Clopidogrel anti-platelet effect: an evaluation by optical aggregometry, impedance aggregometry, and the platelet function analyzer (PFA-100). Platelets 18:491-496, 2007

5. Griessenauer CJ, Dalal SS, Grassi SA, Bhalla T, Schirmer CM: Pharmacy-mediated antiplatelet management algorithm surrounding neurointerventional stenting and flow diversion procedures. World Neurosurg 106:981-982, 2017

6. Griessenauer CJ, Jain A, Enriquez-Marulanda A, Gupta R, Adeeb N, Moore JM, et al: Pharmacy-mediated antiplatelet management protocol compared to one-time platelet function testing prior to Pipeline embolization of cerebral aneurysms: a propensity score-matched cohort study. Neurosurgery [epub ahead of print], 2018

7. Griessenauer CJ, Ogilvy CS, Adeeb N, Dmitriw AA, Foreman PM, Shallwani H, et al: Pipeline embolization of posterior circulation aneurysms: a multicenter study of 131 aneurysms. J Neurosurg [epub ahead of print May 4, 2018. DOI: 10.3171/2017.9.JNS171376]

8. Gupta R, Moore JM, Griessenauer CJ, Adeeb N, Patel AS, Youn R, et al: Assessment of dual-antiplatelet regimen for Pipeline embolization device placement: a survey of major academic neurovascular centers in the United States. World Neurosurg 96:285-292, 2016

9. Gurbel PA, Bliden KP, Hiatt BL, O’Connor CM: Clopidogrel for coronary stenting: response variability, drug resistance, and the effect of pretreatment platelet reactivity. Circulation 107:2908-2913, 2003

10. Holmes DR Jr, Dehmer GJ, Kaul S, Leifer D, O'Gara PT, Stein CM: ACCF/AHA clopidogrel clinical alert: approaches to the FDA "boxed warning": a report of the American College of Cardiology Foundation Task Force on clinical expert consensus documents and the American Heart Association 
endorsed by the Society for Cardiovascular Angiography and Interventions and the Society of Thoracic Surgeons. J Am Coll Cardiol 56:321-341, 2010

11. Hwang G, Huh W, Lee JS, Villavicencio JB, Villamor RB Jr, Ahn SY, et al: Standard vs modified antiplatelet preparation for preventing thromboembolic events in patients with high on-treatment platelet reactivity undergoing coil embolization for an unruptured intracranial aneurysm: a randomized clinical trial. JAMA Neurol 72:764-772, 2015

12. Kim KS, Fraser JF, Grupke S, Cook AM: Management of antiplatelet therapy in patients undergoing neuroendovascular procedures. J Neurosurg [epub ahead of print December 1, 2017; DOI: 10.3171/2017.5.JNS162307]

13. Le Quellec S, Bordet JC, Negrier C, Dargaud Y: Comparison of current platelet functional tests for the assessment of aspirin and clopidogrel response. A review of the literature. Thromb Haemost 116:638-650, 2016

14. McGlasson DL, Fritsma GA: Whole blood platelet aggregometry and platelet function testing. Semin Thromb Hemost 35:168-180, 2009

15. McTaggart RA, Choudhri OA, Marcellus ML, Brennan T, Steinberg GK, Dodd RL, et al: Use of thromboelastography to tailor dual-antiplatelet therapy in patients undergoing treatment of intracranial aneurysms with the Pipeline embolization device. J Neurointerv Surg 7:425-430, 2015

16. Price MJ, Angiolillo DJ, Teirstein PS, Lillie E, Manoukian SV, Berger PB, et al: Platelet reactivity and cardiovascular outcomes after percutaneous coronary intervention: a timedependent analysis of the Gauging Responsiveness with a
VerifyNow P2Y12 assay: Impact on Thrombosis and Safety (GRAVITAS) trial. Circulation 124:1132-1137, 2011

17. Stone GW, Witzenbichler B, Weisz G, Rinaldi MJ, Neumann FJ, Metzger DC, et al: Platelet reactivity and clinical outcomes after coronary artery implantation of drug-eluting stents (ADAPT-DES): a prospective multicentre registry study. Lancet 382:614-623, 2013

\section{Disclosures}

The authors report no conflict of interest concerning the materials or methods used in this study or the findings specified in this paper.

\section{Author Contributions}

Conception and design: Foreman, Griessenauer. Acquisition of data: Foreman, Mooney. Analysis and interpretation of data: Foreman, Enriquez-Marulanda, Mooney, Schmalz, Griessenauer, Harrigan. Drafting the article: Foreman. Critically revising the article: all authors. Reviewed submitted version of manuscript: all authors. Approved the final version of the manuscript on behalf of all authors: Foreman. Statistical analysis: Enriquez-Marulanda. Study supervision: Foreman, Griessenauer, Deveikis, Harrigan.

\section{Correspondence}

Paul M. Foreman: University of Alabama at Birmingham, AL. pforeman@uabmc.edu. 